determination of the direction and magnitude of transfer from a serial list to a derived PA list.

Another question that immediately arises is whether the effects noted in the present study were not simply due to procedural variations, and therefore of little theoretical relevance. Thus, an alternative interpretation of the data might suggest that negative transfer from serial to PA learning is the usual occurrence and positive transfer is merely an artifact of the umusual procedure of vocalizing the stimulus terms in the PA task. Although it is true that the procedures in the Pos $T$ condition were different from those in the standard PA paradigm, such variations may be critical to an understanding of the serial learning process. If one wishes to obtain a relatively pure assessment of what is being transferred from serial learning (i.e., what is learned in serial learning), then it becomes necessary to alter the standard PA paradigm so that the rate of PA learning clearly reflects what was learned. Otherwise PA performance may be merely an artifact of interfering factors built into the standard PA paradigm, and not an adequate reflection of what was learned previously.

Although, by design, the sequential hypothesis was supported in the present experiment, the purpose of the study was not to contrast the traditional hypotheses, but rather to argue that one or more of them was sufficient to explain serial learning and that no new or different basic conception of the serial learning process was necessary. Under appropriate conditions, positional cues may also function in the serial learning process. However, it should be clear that sequential associations cannot be discounted as a major contributor to serial learning effects.

\section{REFERENCES}

CROWDER, R. G., CHISHOLM, D. D., \& FELL, D. A. Transfer from serial to continuous paired-associate learning. Psychonomic Science, $1966,6,455-456$.

CANNON, D. R., \& NOBLE,C.E. Familiarization (M) as a stimulus factor in paired-associate verbal learning. Journal of Experimental Psychology, 1961, 62, 14-23.

JENSEN, A. R., \& ROHWER, W. D. What is learned in serial learning? Journal of Verbal Learning \& Verbal Behavior, 1965, 4, 62-72.

MARTIN, W. L., \& GREENE, W. A. Transfer of interitem associations from serial to pairedassociate learning. Psy chonomic Science, 1966, 4, 295-296.

POSTMAN, L., \& STARK, K. Studies of learning to leam. IV. Transfer from serial to pairedassociated learning. Journal of Verbal Learning \& Verbal Behavior, 1967, 6, 339-353.

SALAFIA, W. F. Articulation versus nonarticulation and the use of irrelevant items as factors in transfer of stimulus famliarization training to a paired-associate task. (Doctoral dissertation, Fordham University) Ann Arbor, Mich.: University Microfilms, 1967. No.67-11, 497.
SCHULZ, R. W., \& TUCKER, I. F. Supplementary report: Stimulus familiarization in pairedassociate learning. Journal of Experimental Psychology, 1962, 64, 549-550.

UNDERWOOD, B. J., \& SCHULZ, R. W. Meaningfulness and verbal learning. Chicago: Lippincott, 1960.

YOUNG, R. K. Tests of three hypotheses about the effective stimulus in serial le arning. Journal of Experimental Psychology, 1962, 63, 307-313. NOTE

1. This research was supported by NSF Institutional Grant GU-1203 to Pairfield University and was presented at the annual meeting of the Eastern Psychological Association, Washington, D.C., A pril 1968.

\title{
Children's response alternation as a function of stimulus duration, age, and trials
}

FRANK D. MILLER, JANE DEE.WANG $T U, G E N E H$. MOFFAT, and SHARON MANLEY, University of South Dakota, Vermillion, S.D. 57069

On each of 81 trials, 4, 7-, and 10-year-old children were required to choose either a red or a green light by making one of two responses. Duration of the chosen light was either $2,4,8,16$, or $32 \mathrm{sec}$, and was varied within Ss. Frequency of alternation was greater for 7-year-olds than for 4-and 10-year-olds, while the latter two groups did not differ. In addition, frequency of alternation decreased across trials but did not vary as a function of stimulus duration.

Hull (1943) postulated that when an organism makes a response, a quantity of reactive inhibition $\left(I_{R}\right)$ is built up which reduces the probability that the response will recur. The total amount of $I_{R}$ produced for a given response is assumed to be an increasing function of the number of occurrences of the response, and of the amount of work involved in making the response. $I_{R}$ is assumed to dissipate spontaneously with the passage of time so that the amount of $I_{R}$ which remains after the occurrence of a response is a decreasing function of the amount of time which has passed since the response occurred. Since the interval between responses increases as stimulus duration (STD) increases, the prediction can be derived from Hull's (1943) model that frequency of alternation will be a decreasing function of STD.

Glanzer (1953) postulates that a quantity of stimulus satiation (IS) develops in each successive moment that an organism perceives a given stimulus, and that Is reduces the organism's tendency to respond to that stimulus. $I_{S}$ is assumed to dissipate with time when the stimulus is not present. Thus, if intertrial interval (ITI) is constant, longer STDs ought to lead to more frequent alternation than shorter STDs, as a result of the accumulation of a greater quantity of $I_{S}$ during the longer STD.

Studies by Croll (1966) and Rabinowitz (1965) involving STDs of 3,6, and $9 \mathrm{sec}$, and 1.5 and $4 \mathrm{sec}$, respectively, have failed to confirm either of these predictions. A significant STD effect was not found in either study. Significant STD effects were obtained, however, by Iwahara \& Sugimura (1959, Experiment 2, Experiment 3) in two experiments employing STDs of $1.5,10$, and $30 \mathrm{sec}$, and 1.5 and $10 \mathrm{sec}$. Frequency of alternation was found to be an increasing function of STD. The results of this study cannot be directly compared with those of Croll (1966) and Rabinowitz (1965) since it differed from them in several respects. First, the latter two studies involved 4- to 5-year-old Ss and 8- to 9-year-old Ss, respectively, while the former study involved 15. to 19-year-old Ss. Age has already been demonstrated to be an effective variable in determining frequency of alternation in children (Weir, 1964 1967). Second, STD and response duration 
(RD) appear to have been confounded in the Iwahara \& Sugimura (1959) study. Subsequent research (Manley \& Miller, 1968) indicates that RD is a variable which affects alternation behavior. Despite these reservations, the Iwahara \& Sugimura (1959) study does suggest that STDs longer than those employed by Croll (1966) and Rabinowitz (1965) may produce effects on children's alternation behavior. The present study was designed to provide further evidence on the effects of STDs of 2, 4, 8, 16, and 32 sec on frequency of alternation and response speeds in 4 to 10-year-old Ss. In addition, the inclusion of these three age groups, 4-, 7-, and 10-year-olds, provides further information on the role of age as a variable in determining frequency of alternation and response speed.

\section{SUBJECTS}

The Ss were 20 children attending the University of South Dakota Nursery School and 40 children attending first and fifth grades at Jolley Elementary School, Vermillion, South Dakota. 1

\section{APPARATUS}

The apparatus consisted of a stimulus panel and a response panel. The stimulus panel, visible through a viewing aperture, contained two light apertures arranged horizontally. Each of the two apertures could be illuminated by a red or a green light. The response panel consisted of two response buttons, one in front of and below each of the two light apertures. A hand pad was equidistant (6 in.) from these two buttons.

\section{DESIGN}

Twenty Ss were assigned to each of three age groups, 4-, 7-, and 10-year-olds. Within each age group, half of the Ss were male and half were female. Within each of the six age-sex subgroups, half of the Ss were assigned to subgroups for which depressing the left button turned on a red light in the left aperture and depressing the right button turned on a green light in the right aperture. For the remaining $S s$ in each age-sex subgroup, the spatial positions of the red and green lights were reversed. On any given trial of the 81 trials administered to each $S$, duration of the light stimulus was $2,4,8,16$, or $32 \mathrm{sec}$. Each $S$ in the 12 age-sex-light position subgroups was randomly assigned to one of four STD sequences. In each of these sequences, each of the five STDs appeared once in each block of five trials with the order of occurrence within a block being randomly determined. For each $\mathrm{S}$, a STD of $8 \mathrm{sec}$ was presented on the last trial to permit each $S$ to have 16 opportunities to alternate under each of the five STDs. The ITI, the period of time from offset of the light to onset of a buzzer signaling the next trial, was $5 \mathrm{sec}$ for all Ss throughout the experiment.

\section{PROCEDURE}

Each S was brought individually to a normally illuminated room and seated in front of the apparatus. The $S$ leaned his head against the viewing aperture and placed his preferred hand on the hand pad, where he kept it except when responding. The $S$ was then instructed that each button turned on a light in the aperture above it and that one light would be red and the other green. Each time he heard a buzzer, $S$ was to push one, and only one, of the two buttons. Response choice and latency were recorded on each trial. Latency was measured to the nearest $0.01 \mathrm{sec}$ from onset of the buzzer to onset of the chosen light.

\section{RESULTS}

The total number of alternations for each $S$ was analyzed using a three-factor analysis of variance (Winer, 1962) with age as the between-Ss factor and STD and trial blocks as within-Ss factors. The 80 alternation trials were arbitrarily divided into four blocks of 20 trials each. Significant main effects were age $(F=5.92, \mathrm{df}=2,57, \mathrm{p}<.05)$ and trial blocks $(F=5.24, \mathrm{df}=3,171, \mathrm{p}<.05)$. The main effect for STD and all interactions were nonsignificant. A post hoc comparison analysis using the Tukey (a) procedure indicated that 7-year-old Ss alternated significantly more than did 4 and 10 yearold Ss $(p<.05)$ with no significant difference in alternation between the latter two age groups. The 4-, 7-, and 10-year-old Ss alternated on $62 \%, 82 \%$, and $64 \%$ of the trials, respectively. $\chi^{2}$ analyses indicated that all three age groups alternated more frequently than would be expected by chance. A t test on Trial Blocks 1 vs 4 indicated a significant decrease in the number of response alternations between Trial Blocks 1 and $4(t=2.34, d f=200$, $p<.05)$.

Latency scores were reciprocalized to produce speed scores and a similar three-factor analysis of variance was performed on these data. Significant main effects included age $(\mathrm{F}=26.44, \mathrm{df}=2,57$, $\mathrm{p}<.05)$ and trial blocks $(\mathrm{F}=10.37$, df $=3,171, p<.05$ ). Only the Age by Blocks interaction was found to be significant $(F=3.85, \mathrm{df}=6,171, \mathrm{p}<.05)$. A Tukey (a) post hoc comparison test indicated that response speeds were significantly different among all three age groups ( $p<.05$ ) with the 10-year-old Ss responding fastest and the 4-year-old Ss responding slowest. A Newman-Keuls test comparing speed scores for the trial blocks indicated a significant increase in response speed from Trial Block 1 to Trial Block $2(p<.05)$ and no significant changes in response speed between Trial Block 2 and Trial Block 4 . DISCUSSION

The present data fails to confirm either the prediction derived from Hull's (1943) $I_{R}$ model or the prediction derived from Glanzer's (1953) IS model concerning the effect of STD on frequency of alternation. These results are in agreement with those of Croll (1966) and Rabinowitz (1965) in indicating that STD does not affect frequency of alternation for Ss in the 4- to 10 -year-old age group. From both models it is possible to predict a decrease in frequency of alternation across trials, and this prediction was confirmed by the present study and by Croll (1966). The results of the Iwahara \& Sugimura (1959) study do suggest, however, that more work needs to be done on the effects of STD and RD on frequency of alternation in older Ss.

Rieber (1966) suggests that the preference for altemation as a response pattern begins at about 4 years of age, persists through Age 8, and drops out by Age 10. The present study would seem to indicate that the alternation tendency is still relatively strong in 10-year-olds. A more accurate observation (Weir, 1967) is that the alternation response pattern does not drop out completely until about Age 12. Also of interest is a comparison of these results with those of Manley \& Miller (1968). Both studies indicate that 7 -year-olds alternate more frequently than other Ss in the 4- to 10-year-old age group.

\section{REFERENCES}

CROLL, W. L. Children's response altemation as a function of stimulus duration, intertrial interval, and trials. Psychonomic Science, 1966, 6, 247-248.

GLANZER, M. Stimulus satiation: An explanation of spontaneous alternation and related phenomena. Psychological Review, 1953, 60, 257-268.

HULL, C. L. Principles of behavior. New York: Appleton-Century-Crofts, 1943.

IWAHARA, S., \& SUGIMURA, T. Studies in spontaneous alternation in human Ss: II. Effects of stimulus-intervals and responding times. Japanese Journal of Psychology, 1959, 39, 42-47.

MANLEY, S., \& MILLER, F. D. Factors affecting children's alternation and choice behaviors. Psychonomic Science, 1968, 13, 65-66.

RABINOWITZ, F. M. Stimulus alternation and response repetition behavior in children. Unpublished doctoral dissertation, University of lowa, 1966.

RIEBER, M. Response alternation in children under different reinforcement schedules. Psychonomic Science, 1966, 4, 149-150.

WEIR, M. W. Developmental changes in problem solving strategies. Psychological Review, 1964, $71,473-490$

WEIR, M. W. Children's behavior in probabilistic tasks. In W. W. Hartup and N. L. Smothergill (Eds.), The young child: Reviews of research. Washington, D.C.: National Association for the Education of Young Children, 1967. Pp. 136-154.

WINER, B. J. Statistical principles in experimental design. New York: McGraw-Hill, 1962. NOTE.

1. The cooperation of Mrs. Helen Montgomery, Director of the University of South Dakota Nursery School, of Mrs. Katherine Walsh, Principal of Jolley School, and of the teachers of both schools is gratefully acknowledged. 